\title{
DIFFUSION OF INNOVATION - THE ADOPTION OF ELECTRONIC COMMERCE BY SMALL AND MEDIUM ENTERPRISES (SMES) - A COMPARATIVE ANALYSIS
}

\author{
Wayne Pease \\ Faculty of Business \\ Wide Bay Campus \\ University of Southern Queensland \\ (pease@usq.edu.au) \\ Michelle Rowe \\ Faculty of Business and Public Management \\ Edith Cowan University \\ (m.rowe@ecu.edu.au)
}

\begin{abstract}
This paper explores the issues that influence the diffusion of innovation as it relates to the adoption of e-commerce by Small and Medium Enterprises (SMEs). It seeks to identify factors facilitating and inhibiting such adoption across contexts - regional, small city and large city. This analysis is cross cultural so the impact of differing economic and cultural issues also will be identified in this research.

Whilst it is generally accepted that the strategic use of information technology (IT) is vital in the marketplace, the rate of such uptake between small and large businesses varies. This research seeks to identify the reasons for this variation. It is critical to understand such factors so that steps can be taken to redress inequity of uptake that might be identified. The paper endeavours to explore factors that are needed to facilitate and encourage IT adoption and so positively influence user acceptance and use of IT innovations in SMEs. Reasons for such uptake as well as strategic approach to the adoption of e-commerce, and variations regarding same also will be considered.

The paper examines existing theory as it pertains to the diffusion of innovation acknowledging the perspective of regional and urban SMEs in various cultural contexts. Empirical investigation exploring this diffusion, the rate of and approach to the uptake by SMEs is planned using a case study methodology.
\end{abstract}

\section{INTRODUCTION}

E-commerce is considered to provide substantial benefits to business, particularly small business. It enables new ways of working to emerge and facilitates an organisation's reengineering. Benefits from e-commerce can be argued to be greater for SMEs (small and medium enterprises) since traditionally they have operated in an uncertain and dynamic environment (Gessin 1996; McRea 1996; Murphy \& Daley 1999; Nooteboom 1994).

SMEs have a critical role to play in the economy. Despite advances in information technology and acceptance by large organisations of such technologies, the same level of adoption is not evident amongst SMEs (Bode \& Burn 2002; Knol \& Stroeken 2001). This paper focuses on the use of e-commerce by SMEs as it relates to their suppliers and other organisations such as intermediaries (B2B) and as it facilitates interaction with customers and potential customers (B2C).

Participation in e-commerce is important from the perspective of commercial transactions but more so in the way it encourages transformation of internal systems and the subsequent influences in terms of cost, responsiveness to customers, customization of offerings and the potential emergence of new products and services (Crawford 1998, p.6).

From this viewpoint it is considered that the study of the uptake of e-commerce by SMEs in differing contexts by way of city size and culture is important. This study addresses the 
research questions -

- does the diffusion of innovation model apply to SMEs in differing contexts - urban and regional and cultural contexts;

- what are the factors that influence the adoption of ecommerce (an innovation) amongst SMEs in differing contexts;

- is the rate of adoption slower for SMEs and to what extent is this a function of city size and location and culture; and

- $\quad$ is there an inequity of the rate of diffusion in regional versus urban areas.

These research questions will be addressed in the proposed research by way of case studies from the Hervey Bay region in Queensland, SMEs located in Perth, Western Australia and Shenyang, a large industrialised city in north east China. These issues and a number of hypotheses identified in the paper will be tested by way of in-depth interviews and case studies of selected SME proprietors from these nominated cities.

\section{UPTAKE OF E-COMMERCE BY SMES}

Crawford (1998, p.20) argued that whilst access to the Internet is relatively inexpensive and readily available, smaller enterprises have been slow in using this as a low cost introduction to e-commerce. The main reasons cited for this reluctance were a lack of time, lack of awareness and a lack of business opportunities. Crawford also noted some impetus for change is vital for e-commerce to be considered.

Brown (2002) identified a number of factors limiting the adoption of e-commerce:

- E-commerce was seen to be a distraction from core business;

- $\quad$ Significant perceived cost and risks associated with e-commerce;

- Lack of strategic vision; and

- Lack of realisation of value/benefits of e-commerce to individual SMEs

The main reason the Internet is used to purchase products is due to its convenience. This is an important factor for regional SMEs to consider, since it highlights an opportunity for them to effectively reach a broader market. Flint \& Herbert (2000) noted that the smaller the business the less likely it is to have a computer that is used daily and that, regional businesses tend not to appreciate the opportunities the Internet provides.

Most SMEs adopt e-commerce in a just by chance or casual manner, rather than as a consequence of systematic consideration and planning (Engsbo et al 2001; Scupola 2002). Jocumsen (2004) describes the decision making process of SMEs as being much less complex compared with what is suggested by theoretical frameworks, with 'extensive use of learned competencies in the form of 'perceived' rationality and the use of rudimentary analytical tools' (Jocumsen 2004, p.668). The lack of real specific awareness which was also identified by Brown (2002) is considered to be a substantial obstacle to the uptake of ecommerce.

Stroeken and Coumans (1998, p.227) note that there is a lack of strategic insight of entrepreneurs/proprietors in relation to 'altered product options as a result of the introduction of IT, the alternative market and customer approach, and the desired forms of co-operation' required to make it work, and this they believe inhibits the application of IT within SMEs. 


\section{THE DIFFUSION OF INNOVATION MODEL}

Understanding how organisations decide to change and do something different (Moseley 2000 ) is critical to making sure such change (and the methods by which this change is introduced), are effective. Research into the Diffusion of Innovation model is vital since it indicates how barriers can render such implementation unsuccessful (Baskerville \& PriesHeje 2001). Rogers (1995) developed the diffusion of innovation model which represents the rate of adoption and the stages through which one passes before adopting innovation. This model has been widely believed to 'best' explain such adoption of innovation.

Innovation is 'an idea, practice or object that is perceived as new by an individual or other unit of adoption' (Rogers 1995, p.11). An innovation is not an invention - from a regional perspective it is 'doing something which did not exist before in a particular territory or technical area' (Vuarin \& Rodriguez 1994, p.15).

Rogers (1995) commented that his six step model was limited and may not always hold true due to its linearity. It can be argued that innovation diffusion is an 'unstructured emergent phenomenon' (Baskerville \& Pries-Heje 2001, p.187) and is too complex to be expressed in a step-like model.

An emerging model of innovation is based on the premise that the Diffusion of Innovation is unstructured and is stimulated by shock - internal or external to the organisation, rather than being a stepwise and rational process (Baskerville \& Pries-Heje 2001; Van de Ven, Angle \& Poole 1989).

Wejnert (2002) posits that the adoption process is not uniform and differs based on the nature of the innovation itself, the innovators and the environmental context within which the organisation is placed. We hypothesise that for regional SMEs these factors differ markedly from those placed in urban regions, particularly with regard to the characteristics of the innovator (the proprietor) as well as the organisation including such things as organisational readiness, attitude to risk, knowledge and experience with e-commerce and so on. Similarly we hypothesise that the economic and cultural context has a significant bearing on rate of and approach to adoption of ecommerce amongst SMEs. These hypotheses will be tested in the research.

Interactive models such as those developed by Burgelman and Sayles (1986) uses both technology-linking and need-linking to realise successful innovation diffusion (Baskerville \& Pries-Heje 2001). In this model a technical breakthrough achieves context within actual or potential market demand (Lucas 1994). The applicability of this approach will be considered across the various contexts included in the study.

From this perspective then for SMEs included in the study the question needs to be considered to what extent do market needs drive technology adoption or vice versa. It is our hypothesis that neither of these occurs for regional SMEs and this in part explains the lack of adoption of e-commerce for SMEs located in regional centres compared with urban centres.

We also hypothesise that the 'shock' which precipitates such adoption for SMEs is reactive or is either a forced decision or occurs just by chance (Engsbo et al. 2001) rather than being strategic in nature.

Diffusion is the 'process by which an innovation is communicated through certain channels over time among the members of a social system' (Rogers 1995, p. 5). This existence of a social system is of great importance when considering the uptake of e-commerce generally and the relative rate of adoption within regional/rural areas compared with urban regions. It is hypothesised that there is a lower level of awareness and a different message 'shared' 
via the social system in which SMEs find themselves. This role of the milieu, taking into account the cultural context, and the subsequent communication within networks (which would include competition) is one that requires further investigation.

Rogers (1995) postulated that innovation was more likely to succeed and be more readily adopted if the relative advantage as a consequence of its introduction was evident; if it was compatible with the organisation, its operations and its view of the world; if it was not 'too' complex, and if it was trialable and could be observed prior to adoption. Local initiatives in the Hervey Bay region have attempted to embody these factors (Pease \& Rowe 2003a, 2003b; Pease Rowe \& Wright 2003).

The diffusion of innovation model identified a number of categories of adopter, based on the speed with which they adopted the innovation. The question is what the profile of innovators and early adopters is, and to what extent are they likely to reside in regional areas, mid sized cities and large industrialised cities? Griffith et al (1986) argued that organisations must possess certain traits if innovation was to have a greater chance of success. These included such things as skill, expertise and experience, management support, approach to risk and leadership. Rogers (1995) and Ruttan (1996) have found that there are three main characteristics that describe innovators and early adopters:

- Their business or professional circumstances: early adopters tend to have a pressing problem, i.e., a clear gap between the actual and the desired and have access to the resources necessary to change their current practice;

- Their personal attributes: early adopters tend to have good formal education, relatively high socio economic status, are socially mobile, open to new ideas and able to cope with risk and uncertainty;

- Their connections: early adopters tend to be exposed to a variety of media, to be well connected in interpersonal networks and to have good contacts with opinion leaders, change agents and other early adopters (Moseley 2000).

Recent research focuses on the importance of the third of these factors, reflecting the view that 'innovation is a social rather than a solely individual process...occurring among a variety of stakeholders rather than as a matter of transfer or dissemination of technology or ideas' (Engel 1997, p.125). Networking and relationship building, for example, amongst SMEs is critical to this. Analysis of this factor within urban and regional areas, and across cultural contexts will be explored in this research.

Essentially the diffusion is about reducing uncertainty 'among members of the social system by means of communication' (Knol \& Stroeken 2001, p.229). For SMEs this is largely by way of interpersonal channels with learning being critical to the adoption and implementation of complex innovations. Promotion of the adoption of e-commerce should include the use of appropriate media to transmit information, the encouragement of early adopters to converse with their peers, targeted training and education programmes, the deployment of facilitators to inform and persuade potential innovators, the identification and support of opinion leaders, the issue of incentives to promote some early trial adoptions, and the promise of ongoing support (Moseley 2000). The extent to which these issues are at play will be considered in relation to the three 'levels' included in this study. It is important to note that the consequence of innovation may not all be positive and this need to be borne in mind by those promoting, in this case, the adoption of e-commerce. The extent to which such innovation is not positive will be investigated across these levels. 


\section{THE CHALLENGE IN REGIONAL/RURAL AREAS}

Rural development requires a mass of innovation decisions to be taken by individuals, households, firms and voluntary and public bodies in areas devoid of scale or agglomeration economies (equating to Engsbo's et al (2001) concept of critical mass), replete with problems relating to remoteness and an urgent need to restructure the economic base (Moseley 2000). Consideration will be given to local initiatives in regional areas to encourage such IT adoption. Such initiatives, where they exist, no doubt reflect the need to restructure the economic base of a region and provide access to infrastructure in regional areas.

Adoption of a new way of doing things by SMEs, amongst others, is arguably fundamental to bringing about change in regional areas insofar as it facilitates the emergence of the new economy. From another perspective the role of SMES in emerging and developing economies such as China is also of interest - what is the role of SMEs similarly in bringing about change and facilitating the emergence of the new economy? From these points alone the issue of e-commerce uptake is worthy of study.

\section{OVERVIEW OF STATE OF PLAY}

There are numerous barriers to the adoption of e-commerce, particularly by regional SMEs. These are largely however internal in nature assuming that external initiatives have been put in place - this however may be quite diverse. Nevertheless these are 'real' potential barriers which need to be addressed. The diffusion of innovations model is important to understanding the dynamics at play in relation to adoption of e-commerce amongst SMEs and this has been outlined above. Empirical research now needs to be conducted to identify the current situation so that appropriate actions can be set in train. This is the intention of this research.

\section{RESEARCH OBJECTIVES}

The objectives of the research are to identify factors influencing the adoption of innovation, in this case e-commerce, by SMEs in regional and urban contexts. Lessons from the diffusion of innovation model will be applied both from the point of view of actual adoption and diffusion of innovation as well as from the regional/urban and cultural context to ensure that initiatives undertaken to promote same are effective. Best practice models and case studies then could be developed to act as a guide to SMEs as they consider adopting ecommerce and other ICT in various contexts.

This paper draws upon and reports part of a long term research project that aims to identify factors affecting the uptake of e-commerce by SMEs comparing urban and regional contexts, and introducing cultural issues.

\section{Research methodology}

The study will be an ongoing one initially involving the case study methodology appropriate to the style of research questions posed - that is concerned with 'how' and 'why' (Morgan 1997; Leonard-Barton, 1988). This methodology was selected given the exploratory nature of the research and since it provided a non-threatening environment 
whereby participants, SME proprietors, could discuss relevant issues in-depth and interact via open discussion.

The structured interview questions from which the case studies will be built will be shaped specifically to identify what SMEs understand by e-commerce, to identify factors triggering or impeding its adoption, to identify time take in considering whether to adopt e-commerce and to identify the benefits from, or expected from, and difficulties associated with ecommerce.

The instrument will be pretested and modified to increase clarity, particularly regarding the understanding of questions given the diversity in cultural context.

Consideration will be given to follow up surveys of SME proprietors in the three contexts. The decision to proceed with these surveys largely is dependent on access to a database of participants in the Chinese context.

The findings from the in depth discussions will be analysed to identify the factors at play both triggering and hindering the adoption of e-commerce within the various contexts. Models will be tested and best practice case studies developed to assist SMEs in various economic, cultural contexts and locations as they consider adoption of ICT and ecommerce. The research seeks to identify variation of factors facilitating/inhibiting such adoption and hopes to achieve the following outcomes:

- $\quad$ add to the body of knowledge so that SMEs are better able to consider and plan potential adoption of ICT and ecommerce;

- contribute to theoretical understanding of ICT and ecommerce adoption by SMEs in various cultural and economic contexts; and

- $\quad$ guide policy makers as they seek to facilitate the adoption of ICT and eCommerce amongst SMEs.

\section{REFERENCES}

Baskerville, R. \& Pries-Heje, J. (2001) “A Multiple-theory analysis of a diffusion of information technology case”, Information Systems Journal, Vol 11, No 3, pp 181212.

Bode, S. \& Burn, J.M. (2002) "Strategies for consultancy engagement for e-business development - a case analysis of Australian SMEs", in Managing Information Technology in Small Business: challenges and solutions, ed. S. Burgess, Idea Group, Melbourne, Australia, pp 227-245.

Brown E (ed.) (2002) Accelerating the Up-take of E-commerce by Small and Medium Enterprises, Small Enterprise Telecommunications Centre (SETEL), viewed 23 March 2003, <http://www.setel.com.au/smeforum2002/final report.pdf>.

Burgelman, R.A. \& Sayles, L.R. (1986) Inside Corporate Innovation: Strategy, Structure, and Managerial Skills, The Free Press, New York

Crawford, J. (1998) NEWS -A Project to get smaller enterprises online, Department of Industry, Science and Tourism, viewed March 23 2003, $<$ http://www.noie.gov.au/publications/NOIE/SME/newsbk.pdf $>$.

Engel P.G.H. (1997) The Social Organisation of Innovation: A Focus on Stakeholder Interaction, Amsterdam, Royal Tropical Institute.

Engsbo, M., Saarinen, T., Salmi, H. \& Scupola, A. (2001) “A framework of Adoption of ECommerce in Networks of SMEs" in Proceedings of IRIS 2001, Ulvik, Norway.

Flint, J. \& Herbert, R. (2000) "Marketing, The Internet \& Regional Small Business", ANZMAC 2000 Conference - Visionary Marketing for the $21^{\text {st }}$ Century, Facing 
the Challenge, Gold Coast, Australia, 28 Nov - 1 Dec.

Gessin, J. (1996) "Impact of electronic commerce on small and medium sized enterprises", Management, Jan-Feb, pp 11-12.

Griffiths, J.M., Ronald, G.H., Ellen, A.S. \& Pat, C. (1986), Diffusion of innovations in library and information science - Final report, Rockville, Md, King Research.

Jocumsen, G. (2004) "How do small business managers make strategic marketing decisions?”, European Journal of Marketing, Vol. 38, No. 5/6, pp 659-74.

Knol, W.H.C. \& Stroeken, J.H.M. (2001) "The Diffusion and Adoption of Information Technology in Small- and Medium - sized Enterprises through IT Scenarios", Technology Analysis \& Strategic Management, Vol 13, no 2, pp 227-246.

Leonard-Barton, D. (1988) "Implementation characteristics of organisation innovations, limits and opportunities for managerial strategies", Communications Research, Vol 15, No 5, pp 603-631.

Lucas, H.C. (1994) "Marketing and technology strategy in a medium-tech start-up", Information \& Management, Vol 27, pp 247-257.

McRea, P. (1996) "Reshaping industry with the Internet", Management, Jan-Feb, pp 7-10.

Morgan, D.L. (1997) Focus groups as qualitative research, ( $2^{\text {nd }}$ edition), Sage, London.

Moseley, M. (2000) "Innovation and Rural Development: Some Lessons from Britain and Western Europe", Planning Practice and Research, Feb-May, Vol 15, Issue 1/2, pp 95-115.

Murphy, P. R. \& Daley, J. M. (1999) "EDI benefits and barriers: Comparing international freight forwarders and their customers", International Journal of Physical

Distribution and Logic Management, Vol 29, No 3, pp 207-216.

Nooteboom, B. (1994) "Innovation and diffusion in small firms: Theory and evidence", Small Business Economics, Vol 6, No 5, pp 327-347.

Pease, W. \& Rowe, M. (2003a) "E-Commerce and Small and Medium Enterprises (SMEs) in Regional Communities", Proceedings of the Chartered Institute of Marketing Inaugural Conference, Sydney, Australia, August 20-22.

Pease, W. \& Rowe, M. (2003b) "Factors Affecting Take-up of Electronic Commerce B Small and Medium Enterprises (SMEs) in the Regional Community of Hervey Bay, Australia”, International Telecommunications Society's Asia-Australasia Regional Conference, Perth, Australia, June 22-24.

Pease, W., Rowe, M. \& Wright, L. (2003) "ICT and Regional Development in Hervey Bay”, International Telecommunications Society's Asia-Australasia Regional Conference, Perth, Australia, June 22-24.

Rogers E. (1995) Diffusion of Innovations, $4^{\text {th }}$ ed, Free Press, New York.

Ruttan, V.W. (1996) "What happened to technology adoption-diffusion research?", Sociologica Ruralis, Vol 36, No 1, pp 51-73.

Scupola, A. (2002) "Adoption Issues of Business-to-Business Internet Commerce in European SMEs", Proceedings of the $35^{\text {th }}$ Hawaii International Conference on System Sciences, Hawaii, USA.

Stroeken, J. \& Coumans, J. (1998) "The actual and potential use of Information Technology in Small and Medium sized enterprises", Promethus, Vol 16, No 4, pp 469-483.

Van de Ven, A.H., Angle, H.L. \& Poole, M.S. (1989) Research on the Management of Innovation: The Minnesota Studies, Harper \& Row, New York.

Vuarin P. \& Rodriguez M. (1994) "Innovation and communication within LEADER", LEADER Magazine, Vol 7, pp 13-16. 
Wejnert, B. (2002) "Integrating Models of Diffusion of Innovations: A Conceptual Framework", Annual Review of Sociology, Vol 28, No 1, pp 297-326. 